\title{
A Hermenêutica Rabínica do Mashal e sua influência no primeiro século EC
}

\author{
Marcelo da Silva Carneiro* \\ Lucas Lima Martins Fridman**
}

\section{Resumo}

O presente artigo tem como objetivo abordar a temática do mashal rabínico na literatura hebraica e sua influência no primeiro século EC. O discurso parabólico presente no judaísmo do segundo templo, acalorado no primeiro século por Shammai e Hillel, ganhou fama universal, após a transmissão massiva do Segundo Testamento, com inúmeras parábolas. No entanto, o estilo literário parabólico, não é uma novidade na escrita hebraica, sendo encontrada em diversos textos do Tanakh (Antigo Testamento). Fato é, que o uso das parábolas, se tornou algo consagrado no meio rabínico, como uma forma de exemplificar e ludificar ideias complexas, democratizando o conhecimento e gerando no ouvinte uma reflexão prática do conceito apresentado. Assim, pretende-se verificar tal influência no primeiro século EC.

Palavras-chave: mashal. Parábola. Tanakh. Hermenêutica. Rabinismo.

\section{Mashal's Rabbinic Hermeneutics and its influence in first century $\mathrm{CE}$}

\begin{abstract}
This article aims to address the theme of rabbinical mashal in Hebrew literature and its influence in the first century CE. The parabolic discourse present in Judaism of the second temple, heated in the first century by Shammai and Hillel, gained universal fame, after the massive transmission of the Second Testament, with countless parables. However, the parabolic literary style is not a novelty in Hebrew writing, being found in several texts of the Tanakh (Old Testament). Fact is, that the use of parables has become something consecrated in the rabbinical environment, as a way of exemplifying
\end{abstract}

* Graduação em Teologia, Doutor e pós-doutor em Ciências da Religião (UMESP), docente permanente no PPG em Ciências da Religião da UMESP e graduação em Teologia da FATIPI. professor.carneiro@hotmail.com. http://lattes.cnpq.br/1538475961681653

** Graduação em Teologia, Mestrando em Teologia. lucaslmfridman@gmail.com; http:// lattes.cnpq.br/7114898487881691. 
and deceiving complex ideas, democratizing knowledge, and generating in the listener a practical reflection of the concept presented. Thus, it is intended to verify this influence in the first century EC.

Keywords: mashal. Parable. Tanakh. Hermeneutics. Rabinism.

\section{La hermenéutica rabínica de Mashal y su influencia en el siglo I EC}

\section{Resumen}

Este artículo tiene como objetivo abordar el tema del mashal rabínico en la literatura hebrea y su influencia en el siglo I EC. El discurso parabólico presente en el judaísmo del segundo templo, calentado en el siglo I por Shammai y Hillel, ganó fama universal, después de la transmisión masiva del Segundo Testamento, con innumerables parábolas. Sin embargo, el estilo literario parabólico no es una novedad en la escritura hebrea, ya que se encuentra en varios textos del Tanaj (Antiguo Testamento). Lo cierto es que el uso de parábolas se ha convertido en algo consagrado en el entorno rabínico, como una forma de ejemplificar y engañar ideas complejas, democratizar el conocimiento, y generar en el oyente una reflexión práctica del concepto presentado. Así, se pretende verificar esta influencia en el siglo I EC.

Palabras clave: mashal. Parábola. Tanakh. Hermenéutica. Rabinismo.

\section{Introdução}

Neste trabalho abordaremos um dos mais importantes recursos de ensino religioso do judaísmo: o mashal; que pode ser compreendido como uma metáfora que busca apresentar uma narrativa baseada no cotidiano para explicar um conceito ético e religioso. É um fato recorrente que o termo normalmente é aplicado como sinônimo da palavra "parábola", o que pode não parecer muito apropriado.

Em nossos questionamentos, promoveremos um debate entre diversos autores, que pesquisaram o tema, para deslindar se de fato o mashal pode ser considerado uma parábola, como comumente aplicado. Além disso, será analisada a sua importância para a manutenção da tradição judaica e a maneira com que seu argumento parte do cotidiano para explicar questões éticas e religiosas.

Começaremos nosso trabalho debatendo sobre as inconsistências geradas pela tradução do conceito de mashal como parabolé que, entre outras coisas, reduz sua principal característica, refletida na tentativa de aplicar uma alegoria secular para apresentar um nimshal, definido como o ensino étnicoreligioso que será apresentado aos fiéis, abordando também sua aplicação literal e metafórica. 
Em seguida, debruçaremos nossos estudos no modo como o mashal é apresentado por todo o Tanach - que os cristãos chamam de Antigo Testamento - abordando a maneira com que são apresentados em todas as suas partes, definidas como Torah, Ketuvim e Neviim. Na terceira parte do nosso trabalho discutiremos a importância do ensino através do mashal nos escritos rabínicos do primeiro século, em especial na escola no rabino Hillel, o Babilônico, e sua busca por promover ensinamentos mais humanizados do judaísmo que foram paralelos ao de Jesus e, sob muitos aspectos, parece tê-lo inspirado. Além disso, iremos abordar a maneira com que Jesus soube utilizar de tradição e inovação do mashal em suas pregações.

Por fim, na última parte, explicaremos a maneira como a criação do Mishná serviu para a conservação e consolidação do mashal como parte da cultura judaica, impedindo inclusive que muitos ensinamentos se perdessem ao longo da história. Entenderemos a importância do mashal para a cultura judaica e como ele permite compreender um pouco mais dos aspectos tradicionais desse povo, tão importante para a história mundial.

\section{O conceito de mashal e sua tradução como parabolé}

Convencionou-se traduzir o termo "mashal", tão caro à didática do judaísmo, como parábola. Uma tradução desajeitada que, em diversos casos, acaba atribuindo uma percepção limitada à sua importância, mas que no seu estrito significado etimológico, pode nos dar pistas sobre a sua origem conceitual.

As três grandes religiões abraâmicas (judaísmo, islamismo e cristianismo) se tornaram conhecidas por sua fé monoteísta. Apesar de ser considerado o primeiro conjunto de crenças cuja fé se baseia em um único Deus, o judaísmo atual conta com a menor quantidade de adeptos do mundo entre as religiões monoteístas, com cerca de 16,5 milhões de judeus espalhados pelo planeta (REUTERS, 2018). O judaísmo cresceu no seio da civilização hebraica, se confundindo com sua própria identidade. Em sua crença, existe apenas um único Deus que se revelou ao mundo através do Tanakh, o livro sagrado dos Hebreus. Dentre os inúmeros ensinamentos religiosos e éticos previstos em seu livro sagrado, muitos deles são representados e ensinados através do mashal, uma figura de linguagem muito rica na narrativa hebraica. (PEUZÉ, 2018).

O mashal consiste em uma pequena narrativa metafórica que busca atribuir uma lição de moral religiosa para o fiel. A proposta principal consiste em promover um paralelo entre um evento cotidiano e secular comum ao 


\section{Marcelo da Silva Carneiro}

Lucas Lima Martins Fridman

ouvinte, com o ensino religioso e ético que se almeja transmitir. De maneira que, ao ouvir aquela narrativa, o fiel consiga extrair o ensinamento pretendido.

No Tanakh, apresentam-se muitos exemplos de mashal. No livro de Shemu'el Beit, traduzido como Segunda Samuel, por exemplo, temos um mashal utilizado pelo profeta Natan para demonstrar o pecado que o rei Davi cometeu ao possuir Bate-Seba, a esposa de Urias:

Adonai mandou a David o profeta Natan; este entrou em sua casa e disse-lhe: Dois homens moravam na mesma cidade, um rico e outro pobre. O rico possuía ovelhas e bois em grande quantidade; o pobre, porém, só tinha uma ovelha, pequenina, que ele comprara. Ele a criava e ela crescia junto dele, com os seus filhos, comendo do seu pão, bebendo do seu copo e dormindo no seu seio; era para ele como uma filha. Certo dia, chegou à casa do homem rico a visita de um estranho, e ele, não querendo tomar de suas ovelhas nem de seus bois para aprontá-los e dar de comer ao hóspede que lhe tinha chegado, foi e apoderou-se da ovelhinha do pobre, preparando-a para o seu hóspede. (2Sm 12,1-4)

Através desta pequena alegoria, proposta pelo profeta Natan, o rei Davi faz um paralelo com sua própria atitude, compreendendo de maneira clara e irrefutável o pecado que ele próprio cometera ao cobiçar a mulher de Urias. Com esse exemplo, se observa que o mashal se faz em narrativas simples, cotidianas e de fácil compreensão que se colocam como forma de argumentar uma lição ética, um saber religioso ou uma reflexão espiritual. Portanto, seu papel é o de exemplificar um pensamento teórico e torná-lo acessível, facilitando a compreensão por parte do ouvinte.

Como já mencionado, o mashal é uma forma frequente e fácil dos rabinos ensinarem seus preceitos religiosos aos fiéis, estando seus ensinos presente no Tanakh ou sendo aplicados em toda sorte de debates éticos e religiosos. Fato é que muitas vezes o termo mashal é utilizado como sinônimo da palavra "provérbio" ou "analogia"; embora com frequência seja aplicada como "parábola". Sobre isso nos elucida Peuzé:

O termo hebraico mashal, traduzido comumente por "parábola" provém da raiz m.sh.l., que significa: 1) comparar; 2) contar um mashal, uma parábola; 3) governar. Nota-se que as duas primeiras acepções podem derivar da raiz protossemítica m.t.l., ao passo que a terceira acepção remeteria a uma raiz protossemítica diferente: $\mathrm{m}$.sh.l. As evoluções fonéticas que intervieram entre o protossemítico e o hebraico bíblico ocultaram esta dupla origem, deixando na superfície da língua um só termo: mashal. (PEUZÉ, 2010, p. 3) 
“A palavra grega parabolē é nascida do verbo "paraballein", e pode ser traduzida como "jogar ao lado de..." o que pode ser entendido como emparelhar ou promover uma comparação (PEUZÉ, 2010). O que, neste caso, significa comparar fatos ou alegorias que inicialmente parecem não ter qualquer simetria, mas que reservam um apontamento ético comum. Em paralelo a isso, a tradição rabínica aplica o termo "mashal" como sinônimo de provérbios, ensinamentos e alegorias.

Essa diferenciação de fato ocorreu quando estes textos foram traduzidos para o grego e posteriormente para o latim. "Porém, a literatura rabínica não utiliza mais esse termo para designá-los, pois o mashal tornouse um termus technicus como uma especialidade e uma natureza bem definida" (PEUZÉ, 2018, p. 125). Em outras palavras, a própria generalização do termo por parte da tradição judaica acabou contribuindo para a confusão acerca do termo.

O que podemos afirmar é que a semelhança entre parábola e mashal se encerra exatamente na "comparação" ou "similaridade", onde se promove um espelhamento alegórico entre um evento cotidiano e um ensino ético. Isso porque, diferente da parábola, o mashal assume sua característica própria quando ascende a mera comparação para apresentar um cunho religioso. Em outras palavras, o mashal existe para fazer o livro sagrado, compreensível (PEUZÉ, 2010). Enquanto metáfora, consiste em promover um espelhamento para apresentar um argumento qualquer. Contudo, sua importância expande este conceito apresentando o nimshal.

Notemos que a maioria das parábolas rabínicas são introduzidas pela fórmula consagrada da parábola: a que isso é semelhante? O essencial é o isto, o propósito do qual a parábola é contada, e não a parábola em si. A parábola é apenas um pavio de ínfimo valor, o essencial é a moeda de ouro ou a pérola preciosa como nos indicaram os sábios. Esta pérola preciosa encontra-se no nimshal (PEUZÉ, 2010, p. 47)

É exatamente no nimshal que o mashal transcende a parábola para atingir sua verdadeira função, importância e identidade, que, no caso, é o senso ético-religioso que difere da parábola. Em outras palavras, é no nimshal que o mashal assume seu caráter religioso e espiritual. Assim, enquanto a parábola limita-se a ocupar apenas o campo da ética, o mashal transcende esta limitação abrigando o conceito de nimshal para incutir uma reflexão ético-religiosa. Isso é o que nos permite deslindar que o uso da parábola como sinônimo de mashal não se faz apropriado por negar uma das mais importantes 
características do povo judeu: revelar e ensinar sua crença monoteísta em um Deus transcendental, através histórias baseadas em elementos imanentes.

\section{$1.1 \mathrm{O}$ uso metafórico e o uso literal do mashal}

O judaísmo é colocado como um misto de religião, filosofia e modo de vida dos povos semitas que configura um dos mais importantes traços culturais do povo hebreu e define sua identidade:

Atualmente o judaísmo é pensado tanto como uma religião quanto como ideologia, tanto como tradição quanto estilo de vida. Mas não é apenas o mito de origem narrado nas Escrituras que traz o sentimento de uma origem comum e de comunidade. Há uma história reconhecida e partilhada de buscas, conquistas, vitórias, derrotas e desterros nas quais heróis, homens comuns e populações inteiras, persistiram em manter a unidade e o sentimento de pertença a um povo, preservando o sentimento de comunidade. Uma história antiga e recente de colonizações, migrações, perseguições, cativeiros e recuperação. (GALINKIN, 2008, p. 89)

O judaísmo, como religião, é fundamental na construção da identidade cultural dos judeus, no sentido de se reconhecerem enquanto povo. Dentre os diversos aspectos da tradição judaica, estão suas histórias e a sua forma de vivenciá-las. O mashal, apresentado pela tradição do Tanakh, que independente de ser real ou metafórico, configura o âmago da hermenêutica do povo judeu, da sua forma de entender a si mesmos, de compreender sua posição diante do mundo e de obter os saberes necessários para exercer o Pirkei Avot (ética dos pais). De sorte que a reflexão que o judeu promove sobre os ensinamentos do mashal é fundamental em seu poder transformador, não importando se sua história é metafórica ou literal.

\section{O uso do mashal no Tanakh}

Normalmente nos referimos ao Tanakh como Antigo Testamento, uma visão cristianizada que baseia toda a análise do povo judeu através da lente nublada da nossa própria percepção cultural e religiosa. Afinal, conceber que existe um "antigo" testamento pressupõe a existência de um "novo" que, na visão do cristão, teria surgido com Jesus, anulando as promessas e ideias do anterior. Tal interpretação parece equivocada uma vez que os judeus não veem seu próprio livro sagrado como antigo, velho, arcaico ou 
ultrapassado. Tampouco o Segundo Testamento (conhecido como Novo Testamento), sugere algo do tipo.

Diferente dessa proposta comumente difundida, os judeus dividem seu livro sagrado em: livro da Lei (Torah), Profetas (Neviim) e escritos (Ketwim). Uma divisão em três partes que abriga todo o necessário para manter a tradição espiritual de seu povo. Fato interessante de ser salientado é de que dentre muitos tipos de ferramentas narrativo-pedagógicas, o mashal está presente. A despeito de não ser o recurso mais comum utilizado, foi o mais adotado posteriormente pelos sábios, por uma razão definida:

$\mathrm{Na}$ literatura rabínica, as parábolas chegam a centenas, ao passo que a Bíblia hebraica não traz senão algumas dezenas. Isso nos indica o quanto os Sábios privilegiaram este meio literário. Uma das razões reside no fato de eles não considerarem o mashal como uma simples comparação, mas sim como um poderoso meio de questionamento. (PEUZÉ, 2010.p.)

\subsection{Mashal na Torah}

A Torah é uma das mais importantes partes do Tanakh; sendo composta pelos cinco primeiros livros da Bíblia - o pentateuco -, trata da aliança estabelecida entre Deus e o povo por Ele escolhido. A Torah é composta pelos livros Bereshit (Gênesis), Shemot (Êxodo), Vayikrah (Leviticos), Bamidbar (Números) e Devarim (Deuteronômio) que juntos contam a história da relação entre os judeus e seu Deus, demonstrando que a associação entre esta divindade e o povo escolhido não se fez livre de rusgas, mas mostrouse firmada em proximidades, afastamentos, culpas, erros, arrependimento e redenção que decorreu ao longo do tempo.

Brad Young (1998, p. 19) salienta que o leitor pode observar o Mashal nas declarações bíblicas sobre Deus e suas ações no mundo, pois essas são exibidas em linguagem de imagens que se movem em cadências rítmicas de poesia hebraica. As obras redentoras de Deus são apresentadas em imagens vívidas de força como em Dt 5,15. A mente oriental tendia a conceber Deus de forma dinâmica em metáforas; Deus é conhecido por seus atos poderosos. Parábolas descrevem Deus em imagens semelhantes.

Nas páginas da Torab o estudante se depara com a ideia de que o próprio Israel poderia vir a ser um mashal para as outras nações (Dt 28,37): "Serás motivo de assombro, de provérbio e de caçoada em meio a todos os povos onde Iahweh te houver conduzido." O famoso rabino medieval Rashi (2018, p. 251) destaca: "Um Exemplo (Mashal): quando uma praga 
terrível recair sobre alguém, as pessoas dirão: 'Isto é como uma praga que aconteceu com o fulano de tal"'. Nesse caso o mashal seria uma ilustração como observou Jeffrey Tigay (1996, p. 266).

Sendo o judaísmo uma religião baseada em um livro sagrado, parece correto imaginar que seu culto seria também alicerçado em ensinos da Torah, ou seja, no estudo dos textos sagrados. Estes estudos ocorrem através do Talmud-Torah.

O Talmud define e dá forma ao judaísmo, alicerçando todas as leis e rituais judaicos. Enquanto o Chumash (o Pentateuco, ou os cinco livros de Moisés) apenas alude aos Mandamentos, o Talmud os explica, discute e esclarece. Não fosse este, não entenderíamos e muito menos cumpriríamos a maioria das leis e tradições da Torá e o judaísmo não existiria. (STEINSALTZ, 2003, p. 1)

O Talmud-Torah reflete, portanto, o âmago da cultura e tradição judaica, sendo seu estudo fundamental para a compreensão da própria identidade cultural deste povo. Desta forma, ensinar a Torah é parte fundamental do ser judeu (PEUZÉ, 2010). Nada mais natural que as reflexões propostas pelo mashal estejam também associadas ao Talmud-Torah, como uma forma de promover estes ensinos.

O mashal como atividade exegética requer esse mesmo dinamismo dos ouvintes e se inscreve assim perfeitamente na perspectiva do TalmudTorá. Da mesma forma que se entra na página do Talmud, se passeia pelo labirinto da Guemará e dos comentários ao seu redor, para se chegar às novas interrogações, assim se encontra na narrativa e no mashal, para se chegar ao nimshal, resultado desvelado pelo caminho percorrido. (PEUZÉ, 2010, p. 69)

Assim, o mashal ajuda a atribuir sentido à Torah, no sentido de exemplificá-la, sendo um importante recurso em seus estudos. "Aponta-se enfim que o mashal se encontra em plena consonância com o mundo do Talmud-Torá por ser, antes de tudo, uma atividade e um questionamento, e por pertencer ao domínio da Torá oral" (PEUZÉ, 2010, p. 69).

\subsection{Mashal nos Ketuvim (Escritos)}

O Ketuvim, que pode ser traduzido como "escritos", é a terceira e última parte do Tanakh e se faz em onze livros dedicados à sabedoria deste povo. Sendo eles: Tehillim (Salmos), Mishlei (Provérbios), Iyov (Jó), Shir ha-Shirim (Cântico dos Cânticos ou Cantares), Shavnot (Rute), Eikhah (Lamentações), kohelet (Eclesiastes), Purim (Ester), Daniel, Eqdras (Esdras e Neemias) e Divrei 
ha-Yamim (Crônicas). Sendo livros que reservam o ensinamento do povo judeu, é normal que também possuam seus meshalim.

O próprio livro de Mishlei ou "Provérbios", se faz em uma coletânea de reflexões e ensinos, muitos dos quais compostos por meshalim elaborados, segundo a tradição, pelo próprio rei Salomão (FARMER, 1991). Um exemplo de Mashal em Provérbios é observado em 18,11: "A fortuna do rico é sua fortaleza: e pensa que é alta muralha.". O livro de Shir ha-Shirim, também atribuído a Salomão, também se faz cheio de alegorias sobre a relação entre Deus e seu povo escolhido.

O livro de Iyov — Traduzido como "Jó" — é um dos maiores exemplos de mashal presentes no Ketuvim. Trata-se de uma alegoria que conta a história de queda e superação de Jó que, a despeito de todo sofrimento infligido, não blasfema contra Deus, mas se mantém firme em sua santidade e por conta disso é abençoado. O texto de Jó 38,4-8 exibe um belo exemplo de Mashal:

Onde estavas, quando lancei os fundamentos da terra? Dize-mo, se é que sabes tanto. Quem lhe fixou as dimensões? — se o sabes —, ou quem estendeu sobre ela a régua? Onde se encaixam suas bases, ou quem assentou sua pedra angular, entre as aclamações dos astros da manhã e o aplauso de todos os filhos de Deus? Quem fechou com portas o mar, quando irrompeu jorrando do seio materno. (Jó 38:4-8)

Com estes exemplos se pode aferir que o uso do mashal é parte fundamental na maneira com que os judeus refletem e externam suas interpretações do mundo.

\subsection{Mashal nos Neviim (Profetas)}

Localizado entre a Torah e o Ketuvim, o Neviim é reconhecido como o livro dos profetas do Tanakh, sendo muito importante para entender seu papel, pois fazem a ponte entre Deus e seu povo escolhido, servindo de emissários da vontade divina para os mortais. É composto por treze livros: Yehoshua (Josué), Shoftim (Juízes), Shmu'el (Primeira e Segunda Samuel), Melakbim (Primeira e segunda Reis), Yeshayabu (Isaías), Yirmiyahu (Jeremias), Yehezq'el (Ezequiel), Hosea (Oseias), Yo'el (Joel), Amos (Amós), Ovadyah (Obadias), Yonah (Jonas), Mikhah (Miquéias), Nakbum (Naum), Habaquq (Habacuque), Tsefania (Sofonias), Haggai (Ageu), Zekharia (Zacarias) e Malakhi (Malaquias).

Segundo suas tradições, os profetas eram responsáveis por divulgar a mensagem de Deus aos homens, sendo o uso de alegorias usualmente aplicado, como no já citado caso em que Natan apresenta os pecados do rei 
Davi através de uma parábola (2Sm 12,1-2), utilizando um mashal para atingir a consciência do soberano. O profeta Isaías, por sua vez, fez uso do mashal para comunicar uma mensagem de repreensão para o rebelde Israel (Is 5,1-7):

Vou cantar ao meu amado o cântico do meu amigo para a sua vinha. O meu amado tinha uma vinha em uma encosta fértil. Ele cavou-a, removeu a pedra e plantou nela uma vinha de uvas vermelhas. No meio dela construiu uma torre e cavou um lagar. Com isto, esperava que ela produzisse uvas boas, mas só produziu uvas azedas. Agora, ó moradores de Jerusalém e homens de Judá, servi de juízes entre mim e a minha vinha. Que me restava ainda fazer à minha vinha que eu não tenha feito? Por que, quando eu esperava que ela desse uvas boas, deu apenas uvas azedas? Agora vos farei saber o que vou fazer da minha vinha! Arrancarei a sua cerca para que sirva de pasto, derrubarei o seu muro para que seja pisada; reduzi-la-ei a um matagal: ela não será mais podada nem cavada: espinheiros e ervas daninhas crescerão no meio dela. Quanto às nuvens, ordenar-lhe-ei que não derramem a sua chuva sobre ela. Pois bem, a vinha de Iahweh dos Exércitos é a casa de Israel, e os homens de Judá são a sua plantação preciosa. Deles esperava o direito, mas o que produziram foi a transgressão; esperava a justiça, mas o que apareceu foram gritos de desespero. (Isaias 5:1-7) ${ }^{1}$

Robert Alter (2011, p. 147) explica que o mashal é usado amplamente pelos profetas, e muitas vezes com tom de ironia e sarcasmo; tal realidade é observada no texto citado acima, bem como em Isaías 14,4-21, e outros mais. O mashal, portanto, parece ser um meio narrativo de levar o leitor a questionarse sobre o óbvio, que parece ser não tão óbvio quando não escavado do texto. Enfim, o que se procura afirmar é que "o mashal se transforma em uma importante ferramenta de questionamento e sem perguntas, não há busca, não há Talmud-Torá. Sem pergunta, não há mashal. Sem pergunta, não há desvelamento de novas realidades" (PEUZÉ, 2010, p. 69).

\section{O uso do Mashal nos escritos rabínicos do primeiro século}

Por tradição os rabinos aplicavam a oralidade para estudar e discutir os textos do Torah, isso mudou quando a comunidade judaica foi desmantelada no ano 70 EC. Uma onda de distúrbios começou a assolar a comunidade judaica, que percebeu a necessidade de pensar em um judaísmo sem templo.

Ver também Joel 1,1-8. 
Com efeito, inúmeros ensinos distorcidos, sem qualquer respaldo na Torah, começaram a aparecer na comunidade judaica. Por conta disso, os rabinos perceberam a importância de mudar e registrar seus estudos em textos com o objetivo de impedir a deturpação dos seus ensinamentos (HERMANN, 1945). Foi assim que o registro oral foi organizado no Talmud, que depois do século II, acabaria sendo redigida pelo rabino HaNasi. No Talmud se organizava as reflexões e ensinos de diversas escolas, sendo as mais famosas aquelas que pertenceram a Shammai (50 aEC. até 30 EC) e Hillel (60 aEC. até 9 EC).

\section{1 - O mashal em Hillel.}

Dentre as muitas escolas de ensino da tradição judaica que foram responsáveis por fomentar a criação do Talmud, as escolas de Hillel e a de Shammai se destacam. A primeira por ser considerada mais flexível e modernizada e a segunda por sua interpretação muito mais ortodoxa e literal da Torah (BARUCH, 2012). Ambos se utilizaram do mashal para representar suas lições e instruir suas interpretações das escrituras, sendo autores de alguns dos diversos provérbios e parábolas fundamentais para a modernização do judaísmo (BARUCH, 2012).

Hillel, também chamado de "o Velho" ou "o Babilônico", ganhou destaque por sua importância, no sentido de propor um judaísmo mais agregador e pelo fato de sua pregação ser contemporânea à de Jesus:

Seguindo a informação de Charlesworth, Hillel, cognominado "o velho", ou "o babilônico", fez seus primeiros estudos sobre a Torá em sua terra natal, Babilônia. Nasceu no ano 60 a.C. vindo a falecer em 20 d.C., vivendo sob as políticas empreendidas por Herodes, o grande (37-4 a.C.), sendo contemporâneo de Jesus de Nazaré. Não se sabe exatamente quando passou a residir em Jerusalém no desejo de completar seus estudos, tendo como diretores os zugot, "pares", Shemayah e Avtalyon. (FRIZZO, 2010, p. 425)

Notável no uso do mashal para admoestar os fiéis acerca da sua visão mais agregadora do judaísmo, o rabino Hillel foi o autor do mashal "Lei de Ouro do Judaísmo" onde se encontra a célebre frase: "Não faça ao outro aquilo que você não gostaria que fosse feito contigo", cuja autoria é tradicional e muitas vezes atribuída a Jesus (FRIZZO, 2010).

Não bastando ter trazido a mais célebre frase do judaísmo, supracitada, Rabi Hillel, se utilizava do mashal para ensinar de forma mais agregadora e amável o judaísmo a todos quantos quisessem se aproximar do conhecimento 


\section{Marcelo da Silva Carneiro}

Lucas Lima Martins Fridman

da Torah. O erudito pesquisador David Stern (1994, p.203) nos conta uma experiência marcante do Rabi Hillel e dos seus meshalim.

O pagão então veio a Hillel e disse-lhe: Mestre, converta-me com a condição de que me designes Sumo Sacerdote, para que eu possa permanecer e servir no altar. Sente-se, disse Hillel a ele, e vou lhe contar uma coisa. Se alguém deseja saudar um rei de carne e osso, não é certo que ele aprenda a fazer suas entradas e saídas? Na verdade, o pagão respondeu: Faça o que parecer melhor aos seus olhos. (STERN, 1994, p. 203)

Rabi Hillel, tinha uma filosofia de ensino da Torah, que como mencionada anteriormente era agregadora, diferente da visão do Rabbi Shammai, seu contemporâneo e fundador de outra casa de interpretação rabínica. O importante nesse mashal, é o fato de que Rabi Hillel já sabia as reais intenções desse homem, mas decide ensiná-lo um princípio éticoreligioso, por isso segue o mashal:

[Disse Hillel:] Você deseja saudar o Rei dos Reis, o Santo, bendito seja Ele: não é certo que você aprenda como entrar no Santo dos Santos, como consertar as luzes, como se aproximar do altar, como colocar a mesa, como preparar a fileira de madeira? O pagão respondeu: Faça o que parecer melhor aos seus olhos. (STERN, 1994, p. 203)

A essa altura, o rabino já lhe teria ensinado uma lição preciosa de preparo para entrar na presença do Deus a quem ele professava crença, mas ele decide ir além no mashal. "Primeiro, Hillel escreveu o alfabeto para ele e o ensinou. Então ele lhe ensinou o livro de Levítico. E o pagão continuou estudando até chegar ao versículo: "Qualquer forasteiro que invadir será morto" (Nm 1,51)". Stern (1994, p. 203) afirma que o homem por sua própria percepção, ao ler os textos bíblicos, percebeu que mesmo Israel tendo sido chamado de "povo de Deus", recebera uma tão forte instrução de não entrar no Santo dos Santos sem preparo, quanto mais ele que era um forasteiro, sem conhecimento do divino. Então, esse homem, depois de pensar, volta ao Rabino Hillel e afirma:

Que todas as bênçãos da Torah repousem sobre sua cabeça. Pois se você fosse como Shammai, o Velho, talvez eu nunca tivesse entrado na comunidade de Israel. A impaciência de Shammai, o Velho, quase me fez morrer neste mundo e no futuro. Sua paciência me trouxe à vida neste mundo e no mundo vindouro. (STERN, 1994, p. 203) 
Assim, Rabi Hillel alcançou seu objetivo e cumpriu o propósito do mashal, ensinando de forma simples, através de uma história, um princípio ético-religioso profundo.

\subsection{O uso do mashal no Segundo Testamento}

Apesar de atualmente o cristianismo não ser considerado parte do judaísmo e constituir uma crença monoteísta própria, nem sempre foi assim, principalmente no que se refere ao protocristianismo (CARNEIRO, 2016). Sua cultura fundamentalmente judaica também faz uso destas alegorias religiosas, sendo comum encontrarmos no Segundo Testamento da Bíblia muitos ensinamentos transmitidos através de meshalim.

Contudo, se percebe que no Segundo Testamento o termo "mashal" acaba sendo traduzido como parábola, uma tradução que limita o conceito, como já debatemos anteriormente. Neste sentido, Jesus teria sido um mestre na aplicação das parábolas, explicando seus conceitos de maneira simples e clara através das histórias que contava aos seus fiéis. Essa ferramenta era comumente utilizada por profetas, seja para anunciar uma mensagem à um povo ou a uma pessoa individualmente, e por esse fato, inferimos que a parábola/mashal era um meio costumeiro pelo qual o Deus de Israel usava para transmitir ensinamentos e advertências ao seu povo. (GONÇALVES, 2010, p. 157)

Ainda que, de alguma forma, Jesus tenha inovado a técnica para criar o seu próprio estilo de narrar histórias dotadas de um ensino religioso, a essência do mashal permaneceu a mesma, nas suas homilias, como veremos adiante:

A parábola neotestamentária na forma como Jesus a empregou retoma a tradição discursiva do gênero tal como utilizado pelos profetas do Antigo Testamento, porém o seu principal enunciador no contexto bíblico do Novo Testamento, Jesus, deu a ele contornos muito próprios, a ponto de hoje se relacionar o gênero à sua autoria. É preciso dizer que é nesta forma homogenérica de captação em que nos deteremos com mais demora para analisar a parábola como gênero/texto captador. (GONÇALVES, 2010, p. 156)

Os sermões de Jesus que nos são apresentados através da leitura do Segundo Testamento bíblico são repletos de parábolas que se utilizam de questões do cotidiano para debater lições religiosas. Sempre buscando se aproximar da visão de mundo dos seus fiéis para promover o paralelo que permitirá a compreensão dos seus ensinamentos, ele parte do imanente para 
atingir o transcendente, em outras palavras, Jesus parte do conhecido para o desconhecido.

Neste sentido, Jesus evidenciava não apenas sua perspicácia em compreender a realidade do seu tempo, as necessidades, angústias, prazeres e orgulhos das pessoas que o cercavam; como também um domínio único deste estilo de narrativa utilizado a séculos pelos profetas. "Ao que se pode conceber que tendo Jesus nascido judeu e sido criado em seu povo, não poderia se eximir desta tradição cultural: 'vemos que Jesus não poderia deixar de se utilizar do expediente das parábolas na pregação do Evangelho, ligando-se, assim, a uma tradição discursiva do uso de narrativas alegóricas breves com um fundo pedagogizante'.” (GONÇALVES, 2010 p.157). Joaquim Jeremias (1986) demonstra que muitas das parábolas de Jesus estão enraizadas nas do Tanakh e uma das parábolas mais famosas de Jesus se encontra em Mc 12,1-12 onde ele fala de uma vinha, de lavradores e de seu dono; esse texto parece ter íntima relação com Isaías 5,1-7.

Dentre as parábolas mais célebres atribuídas a Jesus e presentes no Segundo Testamento da Bíblia, temos a de Lucas 15.11-32, denominada em geral como "Parábola do Filho Pródigo". Nela Jesus tece uma história sobre um rapaz que teria tomado sua herança e abandonado a casa de seu pai para se aventurar pelo mundo e conhecer os prazeres da vida. Segundo a narrativa, a coisa não foi nada bem e logo o jovem estava pobre, desesperado e teria ido buscar auxílio na casa paterna. ${ }^{2}$

Até aqui já se pode salientar a maestria com que Jesus lida com as questões cotidianas, formulando uma história que poderia ter acontecido com qualquer vizinho, mesmo nos dias de hoje, e debatendo aspectos fortemente relacionados com o nosso medo e prazeres do nosso cotidiano: medo da miséria, busca pelo prazer, conceito de família, paternidade, herança, amor verdadeiro, investimento em valores efêmeros, rebeldia, entre tantos outros.

Jesus termina o mashal explicando que o pai da parábola teria recebido o filho de braços abertos e ainda feito uma ceia para celebrar o retorno do filho pródigo. Quando seu primogênito o indagou acerca dos motivos que o levou a receber seu irmão de volta ao lar, mesmo após ter agido de maneira tão insensata, o pai atribui uma lição de moral acerca do amor incondicional de um pai e que, ao mesmo tempo, permite fazer um paralelo com o amor

2 Um estudo detalhado dessa parábola em seu ambiente judaico pode ser encontrado em Haddad (2015, p. 47-75). 
de Deus para com suas criaturas, que mesmo vivendo em rebeldia, acabam sendo recebidas pela divindade.

Notável como em uma história simples e de fácil compreensão, Jesus conseguiu extrair um poderoso ensinamento capaz de expressar exatamente sua percepção de que a fé judaica deveria ser pautada no amor, percepção esta que ele compartilhava com o rabino Hillel que lhe foi contemporâneo. E não seria por acaso que a pauta principal do ensino de Jesus fosse capaz de promover um paralelo com o judaísmo de sua época, afinal:

O Sitz-im-Leben das parábolas da pregação de Jesus e dos meshalim rabínicos é semelhante na primeira metade do século. Vale lembrar que o judaísmo não era monolítico. Diversas correntes religiosas, sociais e políticas o atravessavam, mas pontos fundamentais são compartilhados entre o movimento de Jesus e a corrente farisaica. Não é de se estranhar então que muitos temas são encontrados tanto nas parábolas evangélicas quanto nas rabínicas. (PEUZÉ, 2018, p. 125)

Existe uma evidente proximidade entre a Sitz im leben - palavra alemã aplicada para exegese dos textos bíblicos e pode ser traduzido como "contexto vital" ou "cerne" - das parábolas rabínicas e cristãs. Isso se deve não apenas porque ambas nasceram do mesmo povo e dentro do mesmo contexto político, como também por ostentarem soluções parecidas para os mesmos problemas, soluções estas que já eram ensinadas aos judeus por rabinos importantes, como Hillel. As parábolas de Jesus guardam amplas semelhanças com as parábolas da época, observemos um exemplo ${ }^{3}$ :

3 Os mesmos exemplos se encontram em: PEUZÉ, P. J. A. R. Mashal Rabinico on parabolé? Parábolas dos Evangelhos à luz dos trabalhos de Paul Ricoeur e Yonah Fraenkel. (2018) 
Tabela 1 - Segundo Testamento e Talmud Bavli

\begin{tabular}{|c|c|}
\hline Mateus 22. 1- 14 & T. B. Shabbat 153a \\
\hline $\begin{array}{l}1 \text { Jesus voltou a falar-lhes em parábolas e } \\
\text { disse: } 2 \text { “O Reino dos Céus é semelhante } \\
\text { a um rei que celebrou as núpcias do seu } \\
\text { filho. } 3 \text { Enviou seus servos para chamar } \\
\text { os convidados para as núpcias, mas estes } \\
\text { não quiseram vir. } 4 \text { Tornou a enviar outros } \\
\text { servos, recomendando: 'Dizei aos convi- } \\
\text { dados: eis que preparei meu banquete, } \\
\text { meus touros e cevados já foram degolados } \\
\text { e tudo está pronto. Vinde às núpcias'. } 5 \\
\text { Eles, porém, sem darem a menor aten- } \\
\text { ção, foram-se, um para o seu campo, } \\
\text { outro para o seu negócio, } 6 \text { e os restantes, } \\
\text { agarrando os servos, os maltrataram e os } \\
\text { mataram. } 7 \text { Diante disso, o rei ficou com } \\
\text { muita raiva e, mandando as suas tropas, } \\
\text { destruiu aqueles homicidas e incendiou- } \\
\text {-lhes a cidade. } 8 \text { Em seguida, disse aos } \\
\text { servos: 'As núpcias estão prontas, mas os } \\
\text { convidados não eram dignos. } 9 \text { Ide, pois, } \\
\text { às encruzilhadas e convidai para as núp- } \\
\text { cias todos os que encontrardes'. } 10 E \text { esses } \\
\text { servos, saindo pelos caminhos, reuniram } \\
\text { todos os que encontraram, maus e bons, } \\
\text { de modo que a sala nupcial ficou cheia } \\
\text { de convivas. } 11 \text { Quando o rei entrou para } \\
\text { examinar os convivas, viu ali um homem } \\
\text { sem a veste nupcial } 12 \text { e disse-lhe: 'Amigo, } \\
\text { como entraste aqui sem a veste nupcial?' } \\
\text { ple, porém, ficou calado. } 13 \text { Então disse o } \\
\text { rei aos que serviam: 'Amarrai-lhe os pés e } \\
\text { as mãos e lançai-o fora, nas trevas exterio- } \\
\text { res. Ali haverá choro e ranger de dentes'. }\end{array}$ & $\begin{array}{l}\text { [A coisa se assemelha a] um rei que convi- } \\
\text { dou seus servos para um banquete, mas sem } \\
\text { fixar o tempo. Aqueles que entre eles eram } \\
\text { prudentes se prepararam e se assentaram } \\
\text { na porta da casa do rei, dizendo: 'Por acaso } \\
\text { falta alguma coisa na casa do rei?' Aqueles } \\
\text { que entre eles eram insensatos foram ao seu } \\
\text { trabalho dizendo: 'Ocorre um banquete sem } \\
\text { esforço?' Repentinamente o rei solicitou seus } \\
\text { servos. Os prudentes se apresentaram diante } \\
\text { dele como estavam, devidamente trajados, e } \\
\text { os insensatos tal como estavam, todos sujos! o } \\
\text { rei se alegrou ao ver os prudentes e se irritou } \\
\text { ao ver os insensatos. Ele disse: 'Aqueles que } \\
\text { estão devidamente trajados para o banquete: } \\
\text { que se sentem, comam e bebam. Aqueles que } \\
\text { não estão para tanto: que eles fiquem de pé } \\
\text { e olhem!' }\end{array}$ \\
\hline
\end{tabular}


A semelhança entre a parábola de Jesus em Mateus e a de Yohanan ben Zaccai no Talmud é extensa; tais semelhanças refletem a ideia de que Jesus não só usava linguagem rabínica, mas também tinha interesses comuns com os rabinos de seus dias. ${ }^{4}$ Essa e muitas outras semelhanças têm levado estudiosos a verem Jesus de Nazaré como parte integrante do corpus de rabis de seus dias (SKARSAUNE, 2004; YOUNG, 2007; 1995; NEUSNER, 2008; RAMOS; MATOS, 2019).

Por certo que as parábolas do Segundo Testamento não se encerram após a morte de Jesus tendo ainda muitos meshalim presentes em outros materiais, como um mashal no livro de Atos dos Apóstolos, o que chama a atenção. No contexto, o apóstolo Pedro teria sido convidado para batizar um soldado romano, portanto um "não judeu", que, por isso mesmo, não seguia os mandamentos da Torah e nem era circuncidado. Pedro, então, é acometido por uma visão onde foi convidado a comer animais quadrúpedes, répteis da terra e aves do céu, criaturas consideradas imundas pela Bíblia Hebraica. O apóstolo se negou a comer. Após três convites feitos e negados, uma voz lhe disse: "Ao que Deus purificou, não chames tu de profano" (At 10,15).

O grande debate proposto por esta parábola seria a necessidade de levar a mensagem da nova fé para uma população "não judaica"; crendo que através de Jesus, o Messias, o evangelho deveria ser comunicado sem preconceitos étnicos, cumprindo o que Deus prometera à Abraão em Gênesis 12, dizendo que abençoaria a todas as famílias da Terra. Contudo, o que nos importa aqui é perceber novamente a utilização de uma metáfora, neste caso creditada a uma visão, para atribuir um valor ético-religioso. De sorte que a aplicação do mashal ainda se faz presente nestes primeiros anos do protocristianismo.

\section{A consolidação do mashal na Mishná e nos escritos rabínicos}

Temos analisado como a tradição do mashal se manteve ao longo de todo o processo histórico vivido pelo judaísmo, assim como toda sua ressignificação junto ao cristianismo. Contudo, dentre todas as mudanças ocorridas no judaísmo, a Mishná se faz como uma das mais importantes, sobretudo para a manutenção e consolidação do ensino através do mashal (SHOOK, BLEEFELD, 2001).

Sendo considerada uma das obras mais importantes do judaísmo

4 Para ver a relação entre ambas as parábolas com mais detalhes, cf. Ribeiro, 2015, pp. 29$37 ; 51-75$. 
rabínico, a Mishná, conhecida também como Mixná ou Mixna, pode ser traduzida como "revisão" ou "estudo". Tendo sua origem nos debates de um grupo rabínico, conhecido como Tanaim, teria sido redigida pelo rabino Judá HaNasi.

A Mishná serve como uma organização de inúmeros preceitos orais ensinados desde os tempos dos patriarcas, como Moisés. Segundo o Talmud, a Mishná teria surgido como uma forma de manter viva a tradição do seu povo diante da perseguição praticada pelos romanos. A Mishná rapidamente passou a ser central na tradição do povo judeu e logo passou a ser considerada a obra mais importante para a construção do judaísmo moderno.

A Mishná é o resultado final de um processo redacional, no qual os sábios de Israel não mediram esforços para compilar, por meio de um esmerado trabalho, sempre pautado pela desenvoltura no conhecimento da Torá escrita e oral, concluído em meados do ano 219 d.C. A Torá exige um constante processo de renovação. Tal movimento está dividido entre a pesquisa (Midrash) e o estudo-ensino (Talmud). Ao redigir a Mishná, os sábios atingem um dos estágios desse processo de renovação da Torá. O conhecimento do passado se justifica numa harmonia e coerência com as máximas divinas. (FRIZZO, 2010, p. 423)

A Mishná não surge alicerçada na proposta de criar um novo judaísmo, inovar conceitos ou suplantar valores antigos, ao contrário, sua proposta se encerra em manter viva a tradição do povo judeu através da acurada revisão dos textos dos seus letrados mais proeminentes. "O que, em suas palavras, se faz em "ensinar o passado, tendo em vista o futuro" (FRIZZO, 2010, p. 423).

Todos os ensinos são sintetizados para funcionar como ponto de partida para o estudo da Torah que continua sendo oral. A Mishná é dívida em seis volumes com sessenta e três tratados. Sendo eles: Zeraim (traduzido como Sementes), Moed (Festas), Nashim (mulheres), Neziikin (prejuízos), Kodashim (santidade) e Tahorot (purificação). Os dois primeiros debatem o indivíduo, enquanto Nashim e Nezikin falam do social e os dois últimos da religião e relacionamento com Deus; sempre tentando introduzir de maneira clara e sintética as regras fundamentais da tradição judaica.

A criação da Mishná resultou em uma modernização até então inédita na tradição judaica. Se antes a Torah era ensinada através da oralidade, a partir daquele momento haveria uma escritura para registrar seus ensinamentos. A proposta consistia em criar um único conjunto de regras, leis e ensino que abarcasse todo o povo judeu a fim de impedir eventuais perdas em sua cultura. 
A Passagem do estágio oral das parábolas para o estágio escrito determinou os traços das narrativas, moldando-as a como mashal ou como parabole. Essa passagem acontece por volta de 80 - 90 da Era Comum para os evangelhos. As tradições rabínicas passaram por um processo similar, porém, o seu período de oralidade foi maior. A mishná foi colocada por escrito no início do terceiro século, seguido por numerosas coletâneas (Midrashim, Talmudim) nas quais se encontram muito meshalim. (PEUZÉ, 2018, p. 145)

Se a proposta da Mishná foi preservar a tradição do judaísmo que se perderia se mantivesse sua oralidade, acabou também servindo para preservar a tradição do ensino através do mashal; fazendo com que muitas destas alegorias, ditos e parábolas fossem eternizadas nos textos, conquistando assim sua consolidação e preservação para as gerações futuras.

A Mishná traz alguns meshalim para exemplificar os tratados e tornálos mais acessíveis. Dos muitos meshalim disponíveis nos tratados, um dos mais conhecidos é o da festa de Sukkot, que trata da permanência na sukkah. Em termos gerais, a festa de sukkot é comemorada por judeus de todo o mundo, em lembrança do período em que viveram em cabanas/tendas no deserto. Assim como todas as festas, existem mitsvot (mandamentos) que as acompanham, e juntos dessas mitsvot, surgem perguntas como: Quanto tempo é preciso ficar na sukeah? Por qual motivo eu deveria sair dela? Assim a Mishná Sukkot 2,9 traz um mashal para explicar.

Durante os sete dias [da Festa das Tendas], o homem deve fazer de sua Tenda sua habitação principal e de sua casa uma morada provisória. Se cair a chuva, a partir de qual momento é permitido deixar [a Tenda]? Quando um prato de mingau se estragar [por causa da chuva]. Conta-se essa parábola: a que isto pode ser comparado? A um escravo que veio encher a taça do seu senhor, ele [o senhor] virou a jarra na sua cara. (Mishná Sukkot 2,9)

Conforme bem comenta Peuzé (2010), esse mashal serve para mostrar uma tensão na resposta, e como sempre, levar o leitor à uma reflexão. O autor comenta que nesse "primeiro trecho descreve então uma situação real e objetiva com dois elementos aparentemente antagônicos: de um lado a permanência na suká, de outro a chuva (forte) passando pelos ramos do teto e tornando a permanência difícil" (PEUZÉ, 2010, p. 50). Mas o fato interessante levantado pela segunda parte do mashal é de que o senhor derramou o líquido sobre o servo, de livre e espontânea vontade. Esse fato nos leva a refletir que a chuva é enviada por Deus para tornar a permanência na sukkah impossível, levando assim o fiel a não cumprir o mandamento. 


\section{Marcelo da Silva Carneiro}

Lucas Lima Martins Fridman

O que nos leva a uma pergunta final: Qual o motivo Deus não aceitaria a mitsvot do fiel? Acaso teria ele feito alguma coisa que o tornara indigno de estar na Tenda? Mais uma vez o mashal atinge o objetivo de levar as pessoas à uma profunda reflexão.

Percebe-se que a religião judaica, em sua crença monoteísta direcionada a um Deus que não apenas os criou como também os escolheu, se faz extremamente importante para a criação da identidade cultural do povo judeu. Neste sentido, importa que seus dogmas, regras e valores sejam ensinados de maneira clara e abrangente para que todo judeu, desde o mais erudito até o mais simplório, seja capaz de entender seus preceitos. Assim, o mashal assume uma enorme importância para este povo, devido a sua incrível capacidade de didática onde se parte do mundano para compreender o divino. Um aspecto muito presente na cultura deste povo e que, seja percebido ou não, se constitui em um dos alicerces da sua identidade como judeus.

\section{Considerações finais}

Ao apurar como o mashal se desenhou na cultura judaica ao longo do tempo, tornou-se possível refletir acerca dos esforços deste povo em manter sua visão de mundo e identidade cultural, mesmo diante da influência do contato que tiveram com tantos povos ao longo do tempo. Muito desta unidade, inclusive, se manteve graças ao zelo com que tratam sua religião monoteísta, que demonstra uma enorme capacidade de gerar identidade cultural entre os judeus. Sendo seus ensinamentos religiosos fundamentais para a manutenção dessa crença.

Percebe-se que o uso da palavra mashal como sinônimo de parábola, além de reducionista do seu sentido, empobrece o termo por subtrair dele o aspecto de cunho religioso. Um mashal não seria apenas uma parábola laica, mas uma tentativa de explicar o divino, santificado e sagrado através do uso de exemplos do mundo coloquial e cotidiano. O divino sendo explicado através do mundano. O efêmero e imperfeito como argumento para o entendimento do eterno e perfeito. Uma abordagem magnífica que demostra a simplicidade e genialidade do uso do mashal tanto no discurso religioso, quanto na manutenção da cultura do povo judeu.

Notou-se o empenho dos rabinos em manter a tradição judaica, mesmo diante de tantas intempéries geradas pela trajetória deste povo tão sofrido e a maneira com que se adaptaram ao novo para não perder ou deturpar sua 
cultura, quando se apropriaram da escrita em conjunto da oralidade para manter vivo os ensinamentos na Torah através da criação da Mishná.

Surge a necessidade de novas pesquisas aplicadas na tentativa de analisar a cultura judaica pelo seu próprio prisma, sem que se faça uso de traduções e conceitos limitadores em grego ou latim. Ainda mais, percebemos que um estudo acurado sobre as tradições judaicas, permite compreender um tanto mais da nossa própria maneira de pensar e, mesmo da religião, refletindo aspectos deste povo tão importante para a história do ocidente.

\section{Referências}

ALTER. R. The art of Biblical poetry. New York: Basic Books, 1985.

BARUCH, S. O Talmude e A Escola de Hillel e de Shammai. 16 Nov, 2012. Disponível em: http://judaismohumanista.ning.com/m/discussion?id=3531236\%3ATopic\%3A81107.

BÍBLIA. Bíblia Jerusalém. São Paulo: Paulus, 2002.

BÍBLIA. Traduzida em português por João Ferreira de Almeida. Revista e Atualizada no Brasil. 2 ed. Barueri SP: Sociedade Bíblica do Brasil, 1980.

CARNEIRO, M. Os Evangelhos Sinóticos. Origens, memória e identidade. São Paulo: Fonte Editorial, 2016.

FARMER, K. Who knows what is good? A Commentary on the Books of Proverbs and Ecclesiastes. [S.1.]: Wm. B. Eerdmans Publishing, 1991.

FRIZZO, A. Deuteronômio e Mishná: tradições que se unem na defesa dos pobres ( $1^{\circ}$ Parte). Atualidade Teológica: Ano XIV nº 36, p 419-440, set. a dez./2010.

GALINKIN, A. L. Judaísmo e identidade judaica. Interações: Cultura e Comunidade, vol. 3, núm. 4, p. 87-97, 2008.

GONÇALVES, J. A configuração discursiva do gênero parábola bíblica: entre a captação e a parafrasagem. Veredas Análise de Discurso. V. 14, n²2, p.157 -166, 2010.

HADDAD, F. Jesus fala com Israel. Uma leitura judaica de parábolas de Jesus. São Paulo: Fons Sapientes, CCEJ, 2016.

HERMANN, S. Introduction to the Talmud and Midrash, Jewish Publication Society: Londres, 1945.

JEREmiAS, J. As Parábolas de Jesus. São Paulo: Paulus, 1986.

NEUSNER, J. Un rabino habla con Jesús. Madri: Ediciones Encuentro, 2008.

PEUZÉ, P.J.A.R. Mashal Rabínico ou Parabole? Parábolas dos Evangelhos à Luz dos trabalhos de Paul Ricoeur e Yonah Fraenkel. 2018. 115 f. Tese Doutoral (Doutorado em Letras) - Universidade de São Paulo. São Paulo. 
. O Mashal rabínico (parábola rabínica): comparação ou metáfora? Revista Vértices. $\mathrm{N}^{\circ}$, p.150-156, 2010.

RAMOS, S. M. MATOS, M. M. Jesus: o mestre entre os sábios. São Paulo: Mareio Miranda de Matos, 2019.

RASHI. Torá - Rashi: Sêfer Devarim - Deuteronômio. São Paulo: Maayanot, 2018.

REUTERS, F. RFI: “Há menos judeus no mundo hoje do que em 1939, segundo Israel”. 11 de abril de 2018. Disponível em: https://www.rfi.fr/br/mundo/20180411-ha-menos-judeusno-mundo-hoje-do-que-em-1939-segundo-israel

RIBEIRO, L. D. Convidados ao Banquete Nupcial: Uma leitura de parábolas nos Evangelhos e na Tradição Judaica. São Paulo: Fons Sapientes; CCEJ, 2015.

SHOOK, R.; BLEEFELD, B. Parábolas del Talmud. Buenos Aires, Argentina: Ediciones Obelisco, 2001.

SKARSAUnE, O. À Sombra do Templo. São Paulo: Vida Nova, 2004.

STEINSALTZ, A.R. Morasha: o que é o Talmude. Número 43. Dezembro de 2003. Disponivel em http://www.morasha.com.br/leis-costumes-e-tradicoes/o-que-e-o-talmud. html. Acesso: 17/07/2021.

STERN, David. Parables in Midrash: Narrative and Exegesis in Rabbinic Literature. Massachusetts: Harvard University Press, 1994.

TIGAY, J. The JPS Torah Commentary: Deuteronomy. Jerusalen: The Jewish Publication Society, 1996.

YOUNG, H. B. Meet the Rabbis: Rabbinic Thought and the Teachings of Jesus. Michigan: Baker Academic, 2010.

Jesus the Jewish Theologican. Michigan: Baker Academic, 1995.

The Parables Jewish Tradition and Christian Interpretation. Michigan: Baker Academic, 1998.

Submetido em: 17-8-2021

Aceito em: 29-9-2021 